\title{
USAHA PRODUKSI JAMU TERSTANDAR DI PEDESAAN (VILLAGE JAMOE CENTRE) SECARA AGROINDUSTRI MELALUI TEKNOLOGI 6 M SIMPLISIA MENUJU MASYARAKAT SEHAT CERDAS
}

\section{JAMU HOSPITAL PRODUCTION BUSINESS IN RURAL AGRO INDUSTRY THROUGH TECHNOLOGY 6 M SIMPLISIA TOWARD INTELLECTUAL HEALTHY COMMUNITY}

\author{
Sunarni Zakaria \\ Fakultas Kedokteran Universitas Airlangga, Kampus A Jalan Mayjen. Prof. Dr. Moestopo 47, Surabaya 60132 \\ Telp.031 5030252-3, 5032803. email:drnarni@yahoo.co.id \\ Wurlina \\ FKH. Universitas Airlangga, Kampus C. Jalan Mulyorejo, Surabaya Indonesia 60115. \\ Telp. : +6231-5992785
}

Achmad Basori

Fakultas Kedokteran Universitas Airlangga, Kampus A Jalan Mayjen. Prof. Dr. Moestopo 47, Surabaya 60132 Telp. 031 5030252-3, 5032803.

Nurina Hasanatuludhiyah

Fakultas Kedokteran Universitas Airlangga, Kampus A Jalan Mayjen. Prof. Dr. Moestopo 47, Surabaya 60132 Telp. 031 5030252-3, 5032803.

\section{Dewa Ketut Meles}

FKH. Universitas Airlangga, Kampus C. Jalan Mulyorejo, Surabaya Indonesia 60115.

Telp. : $+6231-5992785$

\begin{abstract}
Abstrak
Bisnis obat herbal merupakan usaha sampingan bagi ibu sebagian besar. Peserta pelatihan dan pelatihan Ipteks bagi Masyarakat (IbM) tidak diorganisir secara profesional. Tujuan program IbM adalah: 1) meningkatkan pengetahuan tanaman jamu 2) memperbaiki skill dalam memilih, mengeringkan, mencampur, menggiling dan membuat simplisia (6M) 3) meningkatkan khasiat dan produksi jamu instan dan 4) untuk mengembangkan sumber daya manusia dalam pengolahan tumbuhan. Metode program IbM bekerja sama dengan UMKM untuk menyelenggarakan Ipteks bagi Masyarakat (IbM) tentang pengetahuan tanaman obat. Pendidikan dan pelatihan kepada peserta kelompok usaha UMKM bahwa khasiat tanaman obat yang digunakan oleh masyarakat, bagaimana membuat teko dan teko empuk dan teknologi $6 \mathrm{M}$ simplicia. Hasil Kegiatan IbM adalah anggota UMKM yang telah menerapkan 1) pembuatan dalam memilah umbi antara daun, batang dan akar 2) mengaplikasikan waktu panen toga 3) cara menghindari kehilangan sifat pengeringan 4) bungkusan herbal diberi label (bedak atau dalam kapsul) dan meningkatkan pendapatan penjual herbal. Disarankan agar kegiatan IbM terus dilakukan setiap tahun untuk memantau perkembangan UMKM agar bisa menjadi pusat tanaman obat dengan melibatkan siswa untuk menciptakan wirausaha baru.
\end{abstract}

Kata kunci: kemasan, ramuan standar, obat herbal instan, simplicia 6M, Tanaman obat herbal

\section{Abstract}

Herbal medicine business is sideline business for mothers largely. Education and training participants of Ipteks bagi Masyarakat (IbM) event not to be organized professionally. The purposes of IbM program are: 1) improve the knowledge of herbal medicine plants 2) improve skilss in selecting, drying, mixing, grinding and make simplicia (6M) 3) increase the efficacy and instant herbal production (dry form) and 4) to develop human resources in the processing of herbs. Methods of IbM program is cooperating with UMKM to held Ipteks bagi Masyarakat (IbM) on knowledge of medicinal plants. Education and training to participants of UMKM business 


\begin{abstract}
groups that the efficacy of medicinal plants used by the community, how to make retrieval and instant emponempon and technology of 6 M simplicia. Results IbM activity is a member of UMKM has already implement 1) manufacture in sorting bulbs between the leaves, stems and roots 2) apply the harvest time of toga 3) ways to avoid losing the drying properties 4) herbal packs are labeled (powder or in capsules) and increased income herbal vendors. It is suggested that activities of IbM held continuously every year to monitor the development of UMKM in order to be become the center of herbs by involving students to create new entrepreneurs.
\end{abstract}

Keywords: Herbs medicinal plants, instant herbs medicine, packaging, simplicia $6 M$, standardized herbs,

\section{PENDAHULUAN}

Hidup sehat merupakan kebutuhan dasar manusia, disamping kebutuhan sandang, pangan, papan dan pendidikan, karena hanya dengan kesehatan tubuh yang prima, dapat menjalankan aktivitas hidupnya, sehingga ada slogan "Kesehatan memang bukan segala-galanya, tetapi tanpa kesehatan kita tidak bisa berbuat apa-apa, bahkan segalagalanya itu mungkin akan sirna". Bertolak dari hal itu maka upaya kesehatan terpadu (sehat jasmani, rokhani dan sosial) mutlak diperlukan baik secara pribadi maupun kelompok untuk mewujudkan Indonesia sehat. Upaya untuk kesehatan meliputi: pencegahan penyakit (preventif), penyembuhan (kuratif), pemulihan kesehatan (rehabilitatif) serta peningkatan kesehatan (promotif). Berbagai cara dilakukan untuk memperoleh kesehatan yang optimal, salah satunya dengan memanfaatkan tanaman obat (TO) yang dikemas dalam bentuk jamu atau obat tradisional (OT). Pengobatan tradisional menggunakan bahan yang berasal dari tumbuhan banyak digunakan dan tetap digunakan oleh masyarakat terutama yang berada di pedesaan kendati membanjirnya obat modern. Ini berarti bahwa jamu yang banyak jenisnya itu mempunyai khasiat menyembuhkan atau meringankan penderitaan, terutama untuk penyakit ringan yang banyak diderita sebagian orang seperti pegal, pegal linu, nyeri kepala, badan lemas, batuk pilek dan sebagainya. Di Indonesia, obat tradisional masih sedikit digunakan di bidang kedokteran, misalnya kumis kucing, temulawak, kayu putih karena sebagian besar masih belum dapat diterima oleh masyarakat karena masih kurangnya penelitian farmakologis (Wurlina dkk 2005, Saptorini 2002).

Seiring dengan perkembangan IPTEK, jamu mengalami modernisasi. Masyarakat yang dinamis kritis mulai menyukai dan mempulerkan ramuan tradisional. Bahan kosmetik tradisioanalpun berperan serta mempertahankan ketradisionalan ramuan bangsa Indonesia. Penelitian takaran, cara meramu dan jenis bahan baku yang digunakan, dilakukan melalui penelitian dan uji coba dan hasil ramuan sesuai dengan pesan para leluhur, dibukukanlah catatan resep ramuan, sehingga tiap pewaris memiliki derivat keunikan dan kerahasian dalam memilih, mengeringkan, meramu, meracik, menumbuk dan membuat (6 M) bahan baku tanaman obat (Simplisia) yang akan digunakan sebagai jamu.

Kelompok usaha jamu "Sido Mulyo" dan Gapoktan (gabungan kelompok tani PKK) yang terletak di desa Torong
Rejo Krajan kecamatan Junrejo- Batu Malang merupakan kelompok ibu-ibu penjaja jamu yang potensial untuk pengembangan jamu tradisional menjadi pemasok jamu yang bersifat agrobisnis dengan menjual jamu bukan dalam bentuk cair namun dalam bentuk kering (bubuk) dengan kemasan yang cukup memadai.

Tujuan dari kegiatan IbM adalah melestarikan usaha jamu tradisional dengan meningkatkan mutu dan khasiat jamu, pengembangan usaha jamu tradisional sebagai lapangan kerja bagi anggota keluarga terutama kaum wanita maupun sebagai sumber pendapatan dengan mendorong untuk menanam sendiri bahan-bahan jamu dipekarangan rumah, eningkatkan pengetahuan tentang usaha jamu tradisional sejak memilih, mengeringkan. meramu, meracik, menumbuk, dan membuat simplisia menjadi jamu dengan standart telah ditetapkan oleh Ditjen POM, Meningkatkan produksi jamu yang berkaitan dengan pengembangan kemampuan ketrampilan dan teknologi $6 \mathrm{M}$ dan jamu instan. Dampak selanjutnya dari peningkatan produksi jamu adalah terjadinya ekspansi skala produksi, mencegah terjadinya terutama wanita bekerja diluarnegeri dengan meninggalkan keluarganya.

Manfaat potensi ekonomi produk dari IbM adalah pendidikan dan pelatihan serta pembinaan dan bimbingan terhadap industri kecil dipedesaan pada kelompok usaha jamu sebagai percontohan dan inti dalam penghasil jamu berkualitas dengan kemasan yang benar dan menarik secara agribisnis sehingga dapat menekan biaya produksi, akhirnya meningkatkan pendapatan. enerapan Iptek pengolahan tanaman obat menjadi jamu diharapkan dapat meningkatkan khasiat, minat pembeli dan nilai jual. Akhirnya diharapkan kelompok usaha penjaja jamu sebagai percontohan (pilot project) daerah lain penghasil tanaman obat.

Manfaat nilai tambah dari sisi Ipteks adalah pendidikan dan pelatihan pengolahan jamu instant serta pembinaan dan bimbingan yang dilakukan pada industri kecil pedesaan kel;ompok usaha penjaja jamu yang terletak di pedesaan diharapkan dapat meningkatkan SDM terutama penerapan teknologi pengolahan tanaman obat menjadi jamu berkualitas dengan standart yang telah ditetapkan oleh Ditjen POM. Adanya produksi jamu dapat meningkatkan pendapatan penjaja jamu, sekaligus meningkatkan kesehatan masyarakat, menciptakan lapangan kerja baru, terutama kaum muda tidak ada urban ke kota. Alih teknologi pengolahan tanaman obat menjadi jamu dengan standart yang telah ditetapkan oleh 
Ditjen POM akan dapat meningkatkan nilai jual. Selain itu teknologi tersebut dapat diterima oleh masyarakat, murah dan mudah dilakukan oleh masyarakat melalui kelompok usaha penjaja jamu serta tepat guna dan berhasil guna. Teknologi tersebut diharapkan merupakan model industri kecil di pedesaan (village drug centre) dan sebagai pilot project produksi jamu yang berkualitas sesuai dengan Ditjen POM.

Manfaat terhadap dampak sosial secara nasional adalah Program ipteks bagi masyarakat (IbM) pengolahan tanaman obat menjadi jamu diharapkan dapat mengembangkan industri kecil dipedesaan dan prospek bisnis dalam produksi jamu secara industri. Usaha rumah tangga (URT) sebagai plasma dari kelompok usaha penjaja jamu sebagai inti diharapkan akan berkembang menjadi kelompok usaha bersama yang berorientasi agrobisnis (KUBA) dalam bidang pengolahan tanaman obat menjadi jamu instant dengan menggunakan teknologi memilih, mengeringkan, meramu, meracik, menumbuk dan membuat (6M) tanaman obat (simplisia) sebagai jamu berkualitas sesuai dengan Ditjen POM. Dengan adanya industri kecil dipedesaan (village drug centre) diharapkan gerakan kembali ke desa segera terwujud. Akhirnya program ini dapat dijadikan sebagai contoh (pilot project) daerah lain atau propinsi lain sebagai usaha produksi jamu sesuai dengan standart yang telah ditetapkan oleh Ditjen POM.

Manfaat bagi tim pelaksana dan perguruan tinggi adalah memperkaya wawasan tim pelaksana tentang kegiatan usaha jamu yang dilakukan oleh pengusaha mitra, tempat sarana diskusi antara pelaksana kegiatan, pengusaha mitra dan mahasiswa dalam memecahkan masalah teknis dan pemasaran jamu, Perguruan Tinggi dapat memfungsikan pelaksananya secara integral untuk melatih kegiatan kewirausaha bagi mahasiswa yang berorientasi agribisnis.

Manfaat bagi kelompok usaha jamu di daerah adalah meningkatkan volume produksi karena pengusaha mendapat tambahan tenaga kerja dari mahasiswa, memperoleh masukan teknis dari tim pelaksana IbM dan dari mahasiswa peserta IbM tentang pengolahan jamu berkasiat dan aman bagi kesehatan, mahasiswa dapat memberikan kontribusi positif sehubngan pengetahuan seperti keselamatan dan kesehatan pekerja, manajemen $6 \mathrm{M}$.

Manfaat bagi mahasiswa dari sisi ketrampilan dan manajemen adalah ketrampilan usaha jamu menjadi meningkat karena mahasiswa terlibat secara langsung pengolahan jamu, mendapat alih teknologi dan transfer pengetahuan khususnya $6 \mathrm{M}$ simplisia yang dihasilkan oleh pengusaha mitra, dapat mendirikan kegiatan wirausaha sesuai dengan basis Iptek yang dimiliki yaitu usaha jamu berkasiat dan aman dikonsumsi dengan standart yang telah ditetapkan oleh Ditjen POM sehingga dapat membuat rencana bisnis sederhana sesuai dengan kemampuan dan biaya yang dimiliki, menguasai aspek teknologi, manajemen (pemasaran, keuangan dan personalia) dengan tujuan mahasiswa dapat mengkaitkan ketiga aspek manajemen tersebut dengan aspek teknis.

\section{METODE PELAKSANAAN}

Kerangka Pemecahan Masalah adalah dalam pelaksanaan kegiatan program IbM melibatkan kerjasama dengan Kelompok penjaja jamu dan Gapoktan (Gabungan kelompok tani PKK) didaerah sehingga Cara pemecahan masalah adalah pendidikan dan pelatihan tentang ragam tanamn obat dan kegunaan serta efek samping, teknis memilih, mengeringkan, meramu, meracik, menumbuk dan membuat (6M) simplisia, produksi jamu dan prospek bisnis, teknik mengemas jamu agar tidak jamuran, budidaya tanamn obat secara mandiri dengan memanfaatkan pekarangan rumah, cara pemetikan, pencucucian, merebus tanaman obat serta waktu dan cara meminum jamu sebagai pencegahan maupun pengobatan

Realisasi Pemecahan Masalah adalah penyelesaian masalah antara anggota kelompok usaha penjaja jamu diselesaikan oleh mereka sendiri melalui forum yang dapat dipakai dalam penyelesaian konflik tersebut adalah forum rembug desa yang melibatkan LKMD, LMD dan LSM. Untuk meningkatkan kualitas dan kuantitas jamu cair maupun jamu bentuk serbuk, bolus maupun kapsul dilakukan penerapan pelatihan dan langsung praktek $6 \mathrm{M}$ simplisia. Teknologi $6 \mathrm{M}$ simplisia yang diterapkan pada kelompok usaha penjaja jamu adalah dapat diterima oleh masyarakat, mudah dilaksanakan, murah harganya serta tepat guna dan berhasil guna. Peningkatan SDM dalam pengetahuan $6 \mathrm{M}$ simplisia dilakukan pendidikan dan latihan pada URT yang ada disekitar UMKM namun tidak menolak peserta berasal dari daerah lain.

Metode yang diterapkan adalah upaya meningkatkan penghasilan melalui pembinaan dan pelatihan pada anggota kelompok usaha jamu tradisional serta penerapan teknologi $6 \mathrm{M}$ simplisia menjadi jamu sesuai badan POM dengan menggunakan alat yang sangat sederhana. Diharapkan petani ikut melestarikan lingkungan dan menjaga kualitas sumber daya alam (SDA) memalui proses analisa dampak lingkungan (AMDAL). Kegiatan program IbM ini menggunakan metode pelatihan dan pembinaan tentang pembekalan Ipteks tentang teknis memilih, mengeringkan, meramu, meracik, menumbuk dan membuat (6 M) bahan baku tanaman obat (simplisia) yang meliputi pengenalan berbagai macam simplisia dengan berbagai kekurangan dan kelebihannya, pengenalan alat sederhana yang akan digunakan untuk memperbaiki kualitas dan kuantitas jamu,

pengetahuan meningkatkan khasiat jamu dengan teknik memilih, mengeringkan, meramu, meracik, menumbuk dan membuat (6 M) simplisia. pengetahuan tentang memasarkan jamu secara bentuk kering (bubuk)dengan kemasan berkualitas agar dapat dipasarkan kedaerah lain antar propinsi 
dan kualitas ekspor, pengetahuan tentang budidaya simplisia dengan pemanfaatan lahan pekarangan dengan hal-hal yang perlu diperhatikan adalah cara pemetikan simplisia, cara pencucian dan pengeringan simplisia, cara merebus ramuan simplisia, waktu dan cara meminum simplisia sebagai obat dan sebagai pencegahan, cara mengetahui sifat dan citarasa simplisia, cara mengemas jamu tanpa bahan pengawet dengan kedap udara. Evaluasi di akhir Program Pengabdian Kepada Masyarakat dengan cara mencatat hasil $6 \mathrm{M}$ simplisia sebagai jamu meliputi adanya peningkatan produksi jamu hasil dari $6 \mathrm{M}$ simplisia, Wawancara pada konsumen jamu hasil dari 6 M simplisia dan peningkatan penjualan jamu hasil dari 6 M simplisia

Untuk mengukur keberhasilan kegiatan program IbM di daerah adalah jamu instant yang diproduksi mempunyai kualitas yang baik, masyarakat dapat mengolah sendiri jamu instant dengan kemasan yang baik dan menarik (bentuk bubuk/powder atau dalam kapsul), masyarakat menyukai jamu instan, keuntungan yang lebih tinggi, diperoleh menjual jamu instant melalui mitra kelompok penjaja jamu dan Gapoktan dibandingkan menjual jamu segar langsung pada masyarakat

\section{HASIL DAN PEMBAHASAN}

\section{Pendidikan dan pelatihan 6 M simplisia}

Peserta pendidikan dan pelatihan $6 \mathrm{M}$ simplisia adalah sebanyak \pm 20 orang terdiri dari kelompok tani tanaman obat, pejual jamu dalam kemasan, penjaja jamu gendong dalam bentuk cair dan kering, karang taruna, kelompok ibu PKK di Kota Batu. Kegiatan dipusatkan di Kota Batu desa Torong Rejo. Dipilihnya daerah tersebut disebabkan banyak petani tanaman obat, yang telah membudidayakan tanaman obat dan dikemas secara sederhana. Dilakukan dialog interaktif antara peserta pelatihan dengan Tim pelaksana. Program IbM juga melibatkan GAPOKTAN (Gabungan kelompok taniPKK) Jun Rejo Kota Batu.

\section{Cara Pengolahan simplisia}

Hasil dari pendidikan dan pelatihan $6 \mathrm{M}$ simplisia yang peserta pelatihan terutama penjaja jamu dari kelompok tani PKK, melaksanakan cara-cara sebagai berikut: 1) Mencuci simplisia dengan bersih, terbebas dari lumpur dan debu 2) Membuat jamu dengan merebus air hingga mendidih 3) Kemasan yang tadinya dari botol plastik (bekas botol Akua) menjadi kemasan dalam botol kaca 4) Kemasan jamu kering dikemas dalam platik yang bersih dan kedap udara 5) Kemasan diberi sedikit keterangan aturan pakai dan kasiatnya.

Peserta pendidikan dan pelatihan pengetahuan tentang tanaman obat terutama penjaja jamu setelah mengetahui teknik memilih, mengeringkan, meramu, meracik, menumbuk dan membuat (6M) simplisia sebagai jamu menghendaki pelatihan seperti ini dilakukan berkesinambungan untuk menambah pengetahuan bagi mereka. Dari pendidikan dan pelatihan tentang pengetahuan tanaman berkhasiat obat hasilnya dapat dilihat pada tabel 1 .

Pejaja jamu gendong tidak hanya menjual jamu dalam bentuk jadi (cair) tetapi juga dalam bentuk serbuk yang dikemas dalam bungkus platik atau dalam bentuk simplisia yang belum dibuat serbuk. Selain itu penjaja jamu juga menjual jamu buatan pabrik dalam bentuk sachet atau bentuk kapsul. Penjaja jamu tidak hanya menjual jamu saja namun juga menjual makan kecil seperti kacang asin, marning (jagung goreng), telur ayam kampung, botok sembukan, berengkesan teri dan alur, permen asam yang dijual bersamasama saat menjajakan produk jamunya.

Pejaja jamu sudah pula menjual jamu instan yaitu temu instan dan empon instan seperti temulawak instan, temu ireng instan, temu rapet instan, jahe instan, kunir instan dan kencur instan dengan metode asal tim IbM.

Tabel 1. Sebelum dan sesudah mengikuti pendidikan dan pelatihan tentang tanaman berkhasiat obat pada penjaja jamu

\begin{tabular}{cll}
\hline No & \multicolumn{1}{c}{ Sebelum dilakukan IbM } & \multicolumn{1}{c}{ Sesudah dilakukan IbM } \\
\hline 1 & $\begin{array}{l}\text { Pembuatan simplisia tidak dibedakan antara daun, } \\
\text { batang dan akar }\end{array}$ & $\begin{array}{l}\text { Pembuatan simplisia dipilah pilah antara daun batang dan } \\
\text { akar }\end{array}$ \\
2 & Belum diketahui waktu memanen toga & Telah diketahui waktu memanen toga \\
3 & Belum diketahui cara mengeringkan simplisia agar \\
tidak hilang khasiatnya & Telah dfiketahui cara mengeringkan simplisia agar tidak hilang \\
4 & Belum diketahui cara mencampur berbagai simplisia & khasiatnya \\
& agar tetap berkhasiat & Telah diketahui cara mengeringkan simplisia agar tidak hilang \\
5 & Menggunakan kemasan seadanya dan belum diberi & Kemasan bagus dan menarik dan telah diberi label cara \\
& label cara pemakaian & pemakaian \\
6 & Antar penjaja jamu masih bersaing & Tidak ada persaingan dan saling membantu \\
7 & Penjaja jamu belum semua tergabung dalam & Penjaja jamu tergabung dalam \\
& kelompok jamu & kelompok untuk memudahkan pemasaran \\
\hline
\end{tabular}


Antara penjaja jamu gendong maupun pedagang jamu tidak ada persaingan satu dengan yang lain, hal ini terlihat diantara mereka terjadi kebiasaan untuk saling memberikan informasi misalnya terdapat pelatihan seperti yang dilakukan tim dari Unair, tentang tempat memasarkan jamu masingmasing, bahkan sampai pada selera pelanggan tanpa ada kekawatiran akan tindakan pengusaha yang lain yang dapat merugikan atau merupakan persaingan diantara mereka.

Kebiasaan yang lain beraku diantara mereka adalah saling menitipkan barang dagangannya untuk dijual sesama rekan pedagang jamu, dengan jenis produk yang sama seperti yang dihasilkan sendiri, sehingga seolah-olah mereka menciptakan sendiri pesaingnya dari sesama pengusaha, memberi kesempatan konsumen untuk menilai produk mana yang paling cocok, diukur dengan kebiasaan meminum jamu, pelayanan sampai didepan rumah, walaupun harga belinya relatif tidak banyak berbeda antara pedagang yang satu dengan yang lain.

Penjaja jamu menggunakan peralatan sangat sederhana dan seadanya, peralatan rumah tangga yang ada sudah cukup untuk membantu proses memproduksi jamu. Peralatan seperti alat penumbuk dari batu atau kayu cukup untuk dapat digunakan, sedangkan panci yang berasal dari aluminium tidak digunakan lagi karena akan mengurangi khasiat dari simplisia itu sendiri.

\section{Diskusi dan Tanya Jawab}

Dari diskusi peserta pendidikan dan pelatihan tanaman obat, tidak hanya bertanya tentang tanaman obat namun juga khasiat tanaman obat untuk antikanker, antibiabetes, sesak nafas, asam urat dan demam berdarah Selain itu diskusi peluang wirausaha yang dapat dilakukan di pedesaan, jangan semua pemuda/pemudi urban kekota namun perlu menciptakan lapangan pekerjaan untuk otoda Kota Batu. Peluang yang dapat dilakukan adalah produksi simplisia sebanyak banyaknya karena sangat prospek. Petani toga menghendaki perguruan tinggi sebagai pusat Iptek ikut berperan dalam peningkatan SDM dengan menerapkan teknologi yang lain. Untuk pemasaran simplisia dapat dipasarkan sendiri oleh UMKM, namun tim pelaksana akan membantu memasarkan produk yang dihasilkan sesuai dengan standar ditjen POM dan telah terdaftar.

\section{SIMPULAN}

Usaha penjaja jamu merupakan usaha sambilan bagi sebagian besar ibu-ibu dan produksi jamu tradisional merupakan usaha keluarga yang dilakukan bersama anggota keluarga sendiri, tanpa memisahkan kegiatan konsumtif dan kegiatan yang produktif sudah mulai digiatkan secara agrobisnis. Usaha penjaja jamu telah membuat temutemuan instan dan empon-empon instan untuk menambah penghasilan. Perhitungan untung rugi selama ini lebih didasarkan kepada selisih antara pengeluaran yang dianggap modal dan penjualan, sudah diperhitungkan biaya untuk tenaga. Proses alih generasi secara alami, karena usaha jamu mempunyai prospek agribisnis yang cukup menjanjikan.

\section{Saran}

Perlu kegiatan pendidikan dan pelatihan pada UMKM dipedesaan terutama penjaja jamu dilakukan secara berkesinambungan. Dinas terkait, tenaga medis puskesmas hendaknya ikut secara aktif dalam pelatihan tanaman sebagai bahan obat tradisonal

\section{DAFTAR PUSTAKA}

Broeke,Y.T. 1987. Pelayanan Kesehatan di Pedesaan Di Jawa Timur. Institute of Cultural Anthropologi/Sociology of Development, Free University Amsterdam, Nederland.

Hakim,A.S. 1988. Bunga Rampai. Petunjuk Praktis Pemanfaatan Tanaman Berkhasiat Indonesia. (Tanpa Penerbit)

Mardisiswojo,S dan H. Radjakmangunsudarso. 1975. Cabe Puyang Warisan Nenek Moyang. (Tanpa Penerbit).

Maheshwari H., 2002, "Pemanfaatan Obat Alami : Potensi dan Prospek Pengem- bangan",http ://rudct.tripod.com./ sem2_012/hera_maheshwari.htm

Marjo, Y.S. 1990. Aneka resep Obat Kuno Mujarab. Penerbit Bintang Timur Surabaya. Indonesia.

Pramono S., 2002, Reformulasi Obat Tradisional, Seminar Sehari "Reevaluasi dan Reformulasi Obat Tradisional Indonesia", Majalah Obat Tradisional \& Fak.Farmasi UGM, Yogyakarta.

Saptorini E., 2000, Efek Samping Tanaman Obat, Sisipan (Mudah, Murah, Manjur) SENIOR,No.58.

Slamet,M. 1987. Pentingnya Pelestarian Usaha Jamu Tradisional Di Jawa Timur. Lemlit Unair.

Wijayakusuma,H.M.H, S. Dalimartha dan A.S. Wirian. 1992. Tanaman Berkhasiat Obat Indonesia. Penerbit Pustaka Kartini.

Wurlina, S. Zakaria, DK. Meles, W. Sastrowardoyo. 2005. Pendidikan dan Pelatihan Tanaman Obat. LPPM. Unair. Surabaya.

Wurlina, S. Zakaria, DK. Meles, W. Sastrowardoyo. 2008. Materi Pendidikan dan Pelatihan Jamu Gendong. LPPM. Unair. Surabaya. 